\title{
Iron Absorption from Breast Milk, Cow's Milk, and Iron-supplemented Formula: An Opportunistic Use of Changes in Total Body Iron Determined by Hemoglobin, Ferritin, and Body Weight in 132 Infants
}

\author{
ULLA M. SAARINEN AND MARTTI A. SIIMES ${ }^{(34)}$ \\ Children's Hospital, University of Helsinki, Finland
}

\begin{abstract}
Summary
Iron absorption was measured by using changes in the calculated total body iron (TBI) in infants on three different milk regimens: breast milk $(n=86)$, home-prepared cow's milk formula $(n=15)$, and proprietary iron-supplemented infant formula $(n=31)$ during the first $\mathbf{4}$ months of life. The TBI was determined as the sum of the hemoglobin iron (HbI) and the body storage iron (BSI). In the latter assessment, we found a close to linear correlation between the concentration of serum ferritin (SF) expressed as the logarithm and the BSI expressed as milligrams per unit of body weight. Accordingly, the BSI could be calculated from SF and body weight. Iron absorption from milk was estimated from the increment of TBI and from the estimated iron intake at different time intervals. From 2-4 months of age the monthly increment of TBI was 33.5 $\mathrm{mg}$ in the iron-supplemented formula group, $20 \mathrm{mg}$ in the breast milk group, and $6.5 \mathrm{mg}$ in the cow's milk group. The differences were statistically highly significant $(P<0.001)$. The calculated percentage intake was about $70 \%$ for breast milk iron, about $30 \%$ for cow's milk iron, and about $10 \%$ for the supplemental iron in infant formula. Our data emphasize the exceptionally high bioavailability of breast milk iron which markedly dropped after the introduction of solid foods at 4 months of age. These data suggest an inhibitory effect of the solid vegetable foods on iron absorption, especially from breast milk. Our findings indicate that exclusive breast feeding is an effective means in preventing iron deficiency in early infancy as an alternative to the use of iron-supplemented infant formulas.
\end{abstract}

\section{Speculation}

Quantitative estimation of body iron stores by serum ferritin and body weight provides a way to calculate the amount of total body iron. This method provides a new way to study iron absorption without the use of radioactive isotopes, and indicates unusually high bioavailability of breast milk iron if the solid foods are introduced late.

Milk feeding represents the basis of nutrition and an essential source of iron during infancy. On the other hand, iron deficiency is a problem after the first 4 months of life. Studies of milk iron absorption are at present most accurately performed by using radioactively labeled iron $(16,17,21,23)$, but complete studies of milk iron absorption would require targer infant series and several doses of isotopes which could hardly be justified in small healthy infants $(12,14)$.

We made an attempt to find a noninvasive method to study iron absorption without using radioactivity in a series of 132 infants, and to estimate iron absorption from milk during defined periods of time and not from single test doses as has been done before. Early infancy was ideal for this purpose because milk was used as the exclusive source of nutritionat iron under controlled conditions that in other respects would meet the physiologic demands of all nutritients.

The TBI was determined as the sum of the $\mathrm{HbI}$ and the BSI. In the latter assessment, bone marrow aspirates (25) and liver samples (27) have been used earlier in infancy. Recently, the determination of SF has also been documented as a valid measure $(I, 15,26)$. It has been calculated that $\mathrm{l} \mu \mathrm{g} \mathrm{SF} /$ liter represents about $8 \mathrm{mg}$ BSI within the range of adult normal values (29). Despite the general usefulness and independence of SF as a criterion of BSI, certain drawbacks are recognizable, especially in infancy and childhood. The use of the above-mentioned figures would result in a marked overestimation in infants, although the changes in their SF concentrations seem to reflect the BSI equally well (26). We initially found that there is a close to linear correlation between the concentration of SF and the quantity of BSI when the former is expressed as the logarithm and the latter per unit of body weight. We took advantage of this finding in order to calculate the quantity of BSI from the SF and body weight. The net retention of milk iron was further estimated from the increments of TBI in infants exclusively on one of three milk regimens, namely, breast milk, home-prepared cow's milk formula, and proprietary, ironsupplemented, infant formula.

\section{SUBJECTS}

Our series consisted initially of 256 healthy newborn infants born at the Helsinki University Central Hospital, with birthweights over $3.0 \mathrm{~kg}$ and a gestational age between 38 and 42 weeks. The infants were seen at 2 weeks, 1, 2, 4, 6, 9, and 12 months old at the Children's Hospital for dietary instructions and blood sampling.

Breast milk was initially recommended for every infant, and the mothers were encouraged to try breast feeding as long as possible. After weaning, one-half of the infants selected randomly at the time of birth were started on a home-prepared cow's milk formula, and the other one-half on a proprietary, infant milk formula (Bona; Chymos Oy, Lappeenranta, Finland) (Table 1). The latter milk was supplemented with $11 \mathrm{mg}$ iron/liter in the form of ferrous gluconate, but the infants on breast milk or home-prepared cow's milk formula received no supplementary iron.

Solid foods were introduced unusually late, at 3.5 months old, according to a strict protocol. Before 4 months of age, only cooked vegetables were given once daily in insignificant tasting doses and ignored in the discussion. Cereals were started at 5 months and meat and eggs at 6 months old. At 2 weeks old, the daily vitamins were started: vitamin D, 1000 IU; vitamin A, 1500 IU: and vitamin C. $20 \mathrm{mg}$. 


\section{STUDY GROUPS}

From the total infant series three study groups were later selected with the following criteria.

\section{BREAST MILK GROUP}

Breast milk was the only source of milk up to 4 months old in 86 infants. At 6,9 , and 12 months old, the breast milk group was restricted to those 56 infants who were weaned after the age of 6 months.

\section{FORMULA GROUP}

Iron-supplemented proprietary formula was started and breast feeding was completely finished before 2 months old in 31 infants, 14 of whom were weaned already before the age of I month.

\section{COW'S MILK GROUP}

Cow's milk formula prepared at home was started and breast feeding completely finished before 2 months of age in 15 infants.

Accordingly, within these groups the respective milk was the only source of food, in the cow's milk group from 2-4 months, in the formula group from 2-4 months (the smaller group of 14 infants from 1-4 months), and in the breast milk group from birth-4 months of age.

\section{MATERIALS AND METHODS}

\section{LABORATORY DETERMINATIONS}

At every visit of the infants, a venous blood sample of about 2.5 $\mathrm{ml}$ was drawn and the weight was recorded. Hemoglobin was measured in a Coulter Counter Model S, and SF was determined in triplicate by a radioimmunometric assay (26).

\section{ESTIMATION OF HbI}

The $\mathrm{HbI}(\mathrm{mg})$ was calculated as $2.74 \times \mathrm{Hgb}(\mathrm{g} / 100 \mathrm{ml}) \times$ body weight $(\mathrm{kg})(5)$. This estimate is based on a blood volume of 80 $\mathrm{ml} / \mathrm{kg}$ (3). These calculations were done for each infant at each age studied.

\section{QUANTITATIVE ESTIMATION OF BSI FROM SF AND BODY WEIGHT}

The concentration of SF in newborns falls within the same range as that in adult males $(8,13,26)$, although the estimates of BSI are about 50 (3l) and $1000 \mathrm{mg}(9)$, respectively. More similar estimates are obtained by expressing these values for BSI in terms of $\mathrm{mg} / \mathrm{kg}$ of body weight (Table 2 ). We studied the correlation between serum ferritin ( $y$ ) and the BSI expressed as $\mathbf{m g} / \mathbf{k g}$ of body weight $(x)$ in more detail by computer. By using individual paired data from our infant material, the best fit was $y=$ $x /(-0.00150 \times+0.132)$. These analyses were based, however, on further assumptions and calculations, because no absolute values

Table I. Composition of milks used in the siudy

Home-pre-

Bona proprie- pared cow's

Breast milk tary formula' milk formula

$\begin{array}{lrrr}\text { Energy (kcal/liter) } & 680 & 675 & 620 \\ \text { Laclose (g/liter) } & 70 & 72 & 80 \\ \text { Proteins (g/liter) } & 11 & 15 & 20 \\ \text { Casein (\%) } & 40 & 40 & 80 \\ \text { Whey (\%) } & 60 & 60 & 20 \\ \text { Fats (g/liter) } & 36 & 35 & 23 \\ \text { Saturated fatty acids (\%) } & 50 & 36 & 73 \\ \text { Unsaturated fatty acids } & 50 & 64 & 27 \\ \text { (\%) } & & & \end{array}$

'In this formula vitamins and minerals were added that are not shown in the table.
Table 2. $S F$ values and iron stores of adult females, adult males, 64 newborn infants, and 64 infants 2 weeks old

\begin{tabular}{lcccc}
\hline & $\begin{array}{c}\text { Adult } \\
\text { females }\end{array}$ & $\begin{array}{c}\text { Adult } \\
\text { males }\end{array}$ & Newborns & $\begin{array}{c}\text { Infanis at } \\
2 \text { weeks }\end{array}$ \\
\hline $\mathrm{SF}(\mu \mathrm{g} /$ liter) & $34^{1}$ & $94^{1}$ & $160^{2}$ & $305^{2}$ \\
Iron stores (mg/kg of & $5^{3}$ & $15^{\prime}$ & $17^{4}$ & $27^{2}$ \\
body weight) & & & & \\
\hline
\end{tabular}

' Cook et al. (8).

${ }^{2}$ Present data.

${ }^{3}$ Dallman (9).

${ }^{4}$ Widdowson and Spray (31).

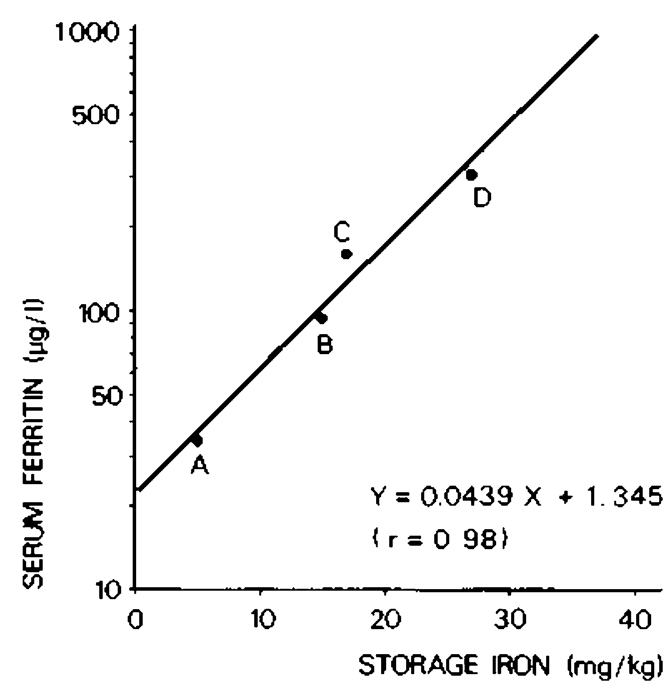

Fig. I. Linear regression of four paired mean values of SF and iron stores $/ \mathrm{kg}$ of body weight. A, adult females; $B$, adult males: $C$, newborn infants: $D$, infants 2 weeks old (Table 2).

for BSI were available. For this reason we selected to use four mean values with acceptable assumptions (Table 2) and found a linear positive correlation between the logarithm of SF and BSI as $\mathrm{mg} / \mathrm{kg}$ (Fig. 1). This correlation line was close to the previously mentioned curve within the normal range of SF values. The four mean values were determined as follows:

$A$ and B. The values for SF and BSI for adult females (A) and males $(B)$ were obtained from the literature $(8,9)$ and converted into $\mathrm{mg} / \mathrm{kg}$ of body weight by using a body weight of $70 \mathrm{~kg}$ for males and $60 \mathrm{~kg}$ for females (Table 2).

C. In our infant series of 256 newborns, there were 95 cord blood samples available. The median of the SF values at birth was used. The value of BSI at birth was obtained from the literature $(22,31)$ (Table 2 ).

D. The values of 64 infants from our series who were 2 weeks old were used (Table 2). We wanted to avoid great variation in the amount of BSI at birth, since the same average value for TBI at birth was assumed for each infant (3I), and, therefore, only those 64 infants with cord blood SF within the $68 \%$ range were selected from the 95 newborns with available cord blood samples. This range, obtained geometrically, was $100-250 \mu \mathrm{g} /$ liter and close to $\pm I$ SD after logarithmic transformation. The BSI at 2 weeks old was calculated by subtracting the actual $\mathrm{HbI}$ at 2 weeks old from the TBI at birth. The $\mathrm{HbI}$ was calculated as explained above, whereas the TBI at birth was based on a figure of $75 \mathrm{mg}$ of iron $/ \mathrm{kg}$ (31). The BSI values were calculated individually and the average BSI/ $\mathrm{kg}$ of body weight and the median of SF values were used (Table 2). The available estimates of physiologic loss of iton during the early weeks of life range from $0.03 \mathrm{mg} / \mathrm{kg} /$ day up to about $1 \mathrm{mg} / \mathrm{kg} /$ day $(4,6,11,30)$. In the present calculations, the dietary iron and the physiologic loss of iron during the first 2 weeks of life were ignored. 